Bài báo khoa học

\title{
Nghiên cứu quy trình cảnh báo nguy cơ cạn kiệt, thiếu nước phục vụ quản lý tài nguyên nước hiệu quả dựa trên giá trị kinh tế sử dụng nước
}

\author{
Lê Thị Mai Vân ${ }^{1 *}$, Nguyễn Hùng Anh ${ }^{1}$, Đoàn Quang Trí ${ }^{2}$, Bùi Thị Bích Ngọc ${ }^{1}$, Trương \\ Văn Hùng ${ }^{1}$ \\ ${ }^{1}$ Trung tâm Quy hoạch và Điều tra tài nguyên nước quốc gia; lethimaivantnn@gmail.com; \\ hunganhtnn@gmail.com; bichngoc209hunre@gmail.com; \\ truongvanhung888@gmail.com. \\ ${ }^{2}$ Tạp chí Khí tượng Thủy văn, Tổng cục Khí tượng Thủy văn; \\ doanquangtrikttv@gmail.com.
}

*Tác giả liên hệ: lethimaivantnn@gmail.com; Tel: +84-982420298

Ban Biên tập nhận bài: 12/7/2021; Ngày phản biện xong: 23/8/2021; Ngày đăng bài: 25/11/2021

Tóm tắt: Nguy cơ cạn kiệt, thiếu nước đang là vấn đề nóng ở mọi quốc gia trên thế giới và Việt Nam. Việc cảnh báo, dự báo, quản lý tài nguyên nước là cơ sở để xác định rủi ro, đưa ra các giải pháp trong quản lý, sử dụng nguồn nước hiệu quả. Nghiên cứu dựa trên phương pháp RIM và xác định rủi ro về thiệt hại kinh tế các ngành sử dụng nước trong bối cảnh hạn hán, thiếu nước dựa trên các cảnh báo về tài nguyên nước trên lưu vực sông Sê San. Kết quả xác định giá trị kinh tế sử dụng nước (GTKTSDN): Chăn nuôi 472.602,74 đồng $/ \mathrm{m}^{3}$; Công nghiệp 389.767,41 đồng $/ \mathrm{m}^{3}$; Thủy sản $12.130,53$ đồng $/ \mathrm{m}^{3}$; Nông nghiệp 5.450,98 đồng $/ \mathrm{m}^{3}$. Xác định thiệt hại, rủi ro về kinh tế sử dụng nước với kịch bản năm 2030 đứng đầu là chăn nuôi với hơn $2.585,14$ tỉ đồng, tiếp là công nghiệp, thủy sản và nông nghiệp tương ứng1.691,59; 99,96; 98,44 tỉ đồng/năm. Quy trình cảnh báo nguy cơ cạn kiệt, thiếu nước phục vụ quản lý tài nguyên nước hiệu quả dựa trên giá trị kinh tế sử dụng nước hỗ trợ rất tốt cho công tác quản lý, quy hoạch hiệu quả tài nguyên nước.

Từ khóa: Giá trị kinh tế sử dụng nước (GTKTSDN); Tài nguyên nước (TNN); Cảnh báo nguy cơ cạn kiệt; Hạn hán thiếu nước.

\section{1. Đặt vấn đề}

Trong bối cảnh hiện nay, sự phát triển dân số cùng với việc gia tăng các nhu cầu sử dụng nước phục vụ các hoạt động dân sinh kinh tế, khan hiếm, ô nhiễm tài nguyên nước cùng với biến đổi khí hậu toàn cầu làm cho vấn đề tài nguyên nước trở nên cấp bách hơn bao giờ hết. Vì vậy, dự báo, cảnh báo về những diễn biến tài nguyên nước trong tương lai đã trở thành vấn đề vô cùng quan trọng trong quản lý tổng hợp tài nguyên nước, phát triển ổn định kinh tế-xã hội [1].

Vai trò của cảnh báo hạn hán, thiếu nước và đánh giá giá trị kinh tế sử dụng nước cũng là mấu chốt trong quản lý tổng hợp tài nguyên nước đối với các ngành sử dụng nước với 4 nguyên tắc về quản lý tổng hợp tài nguyên nước (QLTHTNN) đã được đưa ra (gọi tắt là nguyên tắc Dublin) trong đó nguyên tắc 4: Nước có giá trị kinh tế trong mọi hình thức sử dụng mang tính cạnh tranh và cần được coi như một loại hàng hóa có giá trị kinh tế [2]. Trên 
thế giới nhóm nghiên cứu lượng hóa giá trị kinh tế sử dụng nước được phân dựa trên nhóm mô hình lý thuyết [3-6] và mô hình thực nghiệm [7-13] để xác định giá trị của nước đối với các ngành.

Tại Việt Nam xác định giá trị kinh tế sử dụng nước của các ngành ở Việt Nam là vấn đề mới và phức tạp bởi đây là bài toán kinh tế-kỹ thuật. Hiện chưa có nhiều nghiên cứu định giá giá trị kinh tế sử dụng nước của các ngành, tuy nhiên, một số báo cáo [14] đã đưa ra giá trị hiệu quả sử dụng nước của một số ngành chủ yếu trên 13 lưu vực sông (LVS) lớn ở Việt Nam. Nghiên cứu [15] sử dụng mô hình GAMS trong phân tích kinh tế nước trên LVS Lá Buông; nghiên cứu [16] đã áp dụng phương pháp giá trị chi phí-lợi ích để suy ra giá trị của nước từ đường cầu dẫn xuất của nước; nghiên cứu [17] bước đầu thiết lập phương trình đường cầu để tính toán. Tuy nhiên, ứng dụng thực tiễn cho thấy mức độ đáp ứng thông tin số liệu còn gặp nhiều khó khăn. Các nghiên cứu chuyên biệt về xác định GTKTSDN để đánh giá vai trò của cảnh báo hạn hán, thiếu nước còn khá ít, khiêm tốn về cả số lượng các nghiên cứu và các công bố, trích dẫn trong nước. Đặc biệt là nghiên cứu về GTKTSDN trong bài toán quản lý tài nguyên nước mặt với bối cảnh hạn hán, thiếu nước là chưa có.

LVS Sê San với đặc thù là lưu vực sông liên tỉnh, liên quốc gia nắm vị trí quan trọng là một trong những nhánh chính của sông Mê Công trong 20 năm qua đã trải qua quá trình phát triển nhanh từ thủy điện, khai mỏ, thủy lợi, nông nghiệp đến khai thác gỗ hợp pháp và bất hợp pháp. Tình trạng này gây ra lũ quét, hạn hán, suy giảm lượng đánh bắt cá, thay đổi dòng chảy sông, ô nhiễm, mất đa dạng sinh học và những vấn đề khác tác động đến các cộng đồng địa phương ở cả hai quốc gia. Mục đích với những kết quả nghiên cứu đưa ra sẽ góp phần đưa ra bức tranh về giá trị của nước thông qua giá trị kinh tế sử dụng nước nhằm hoàn thiện quy định kỹ thuật về cảnh báo, dự báo tài nguyên nước nói chung và cảnh báo hạn hán, thiếu nước nói riêng. Quy trình hoàn thiện hỗ trợ ra quyết định cho các cấp quản lý trong việc xây dựng các chính sách, văn bản quy phạm pháp luật trong lĩnh vực, ngành có liên quan tới sử dụng tài nguyên nước.

\section{Phương pháp nghiên cứu và thu thập số liệu}

\subsection{Tổng quan LVS Sê San}

Sông Sê San là phụ lưu bờ trái của sông Mê Công, bắt nguồn từ phần phía Bắc cao nguyên Gia Lai-Kon Tum, chảy trên lãnh thổ hai nước Việt Nam và Campuchia và nhập vào sông Srê Pốk gần Stung Treng. Sông Sê San phía Việt Nam có lưu vực rộng 11.465 km². Phía Bắc giáp sông Thu Bồn; phía Nam giáp sông Ba, IaĐrang; phía Đông giáp sông Trà Khúc, sông Ba; phía Tây giáp Lào và Camphuchia. Sông có hai chi lưu là Krông Pôkô ở phía hữu ngạn và Đắk Bla phía tả ngạn. Sông Đắk Bla đổ vào sông Sê San từ bờ trái; tính đến trạm thủy văn Kon Tum có diện tích lưu vực là $2.968 \mathrm{~km}^{2}$ và chiều dài sông là $123,4 \mathrm{~km}$. Sông Krông Pôkô có diện tích lưu vực $3.230 \mathrm{~km}^{2}$ với chiều dài sông là 125,6 km. LVS Sê San phía Việt Nam có diện tích $11.465 \mathrm{~km}^{2}$. Trên lưu vực Sê San có lượng mưa trung bình nhiều năm là $2120 \mathrm{~mm}$ vào loại trung bình. Lượng mưa năm có xu hướng tăng dần từ thấp đến cao và theo thời gian cũng có nhiều biến đổi. Mưa được phân thành 2 mùa: mùa mưa từ tháng $\mathrm{V}$ đến tháng $\mathrm{X}$, mùa khô từ tháng XI đến tháng IV năm sau.

LVS Sê San gồm lãnh thổ của 2 tỉnh Kon Tum và Gia Lai. Theo tổng điều tra dân số năm 2018 lưu vực sông Sê San có 959.195 người thuộc 2 tỉnh Kon Tum và Gia Lai với số dân lần lượt là 494.463 và 464.731 người. Nông nghiệp là ngành sử dụng nước lớn trên LVS Sê San, tổng số công trình thuỷ lợi phục vụ tưới tiêu trên LVS Sê San bao gồm 125 công trình hồ chứa thuỷ lợi với năng lực tưới là 22.470 ha. Ngoài ra, trên LVS Sê San có 74 đập dâng lớn nhỏ và 17 trạm bơm với diện tích tưới là 2.580 ha [18]. 


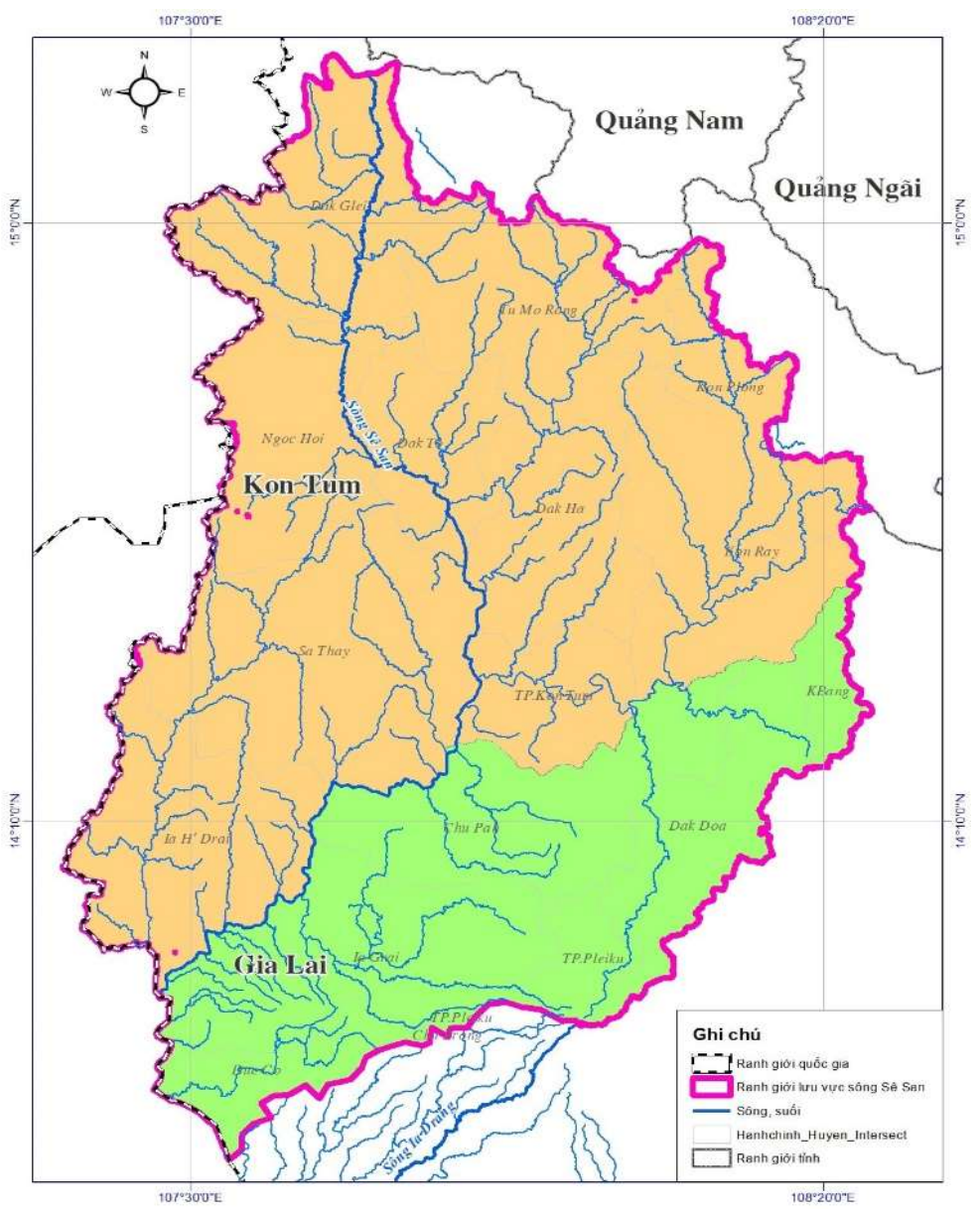

Hình 1. Lưu vực sông Sê San [19].

\subsection{Phương pháp nghiên cứu}

Nghiên cứu dựa trên các kinh nghiệm của thế giới và trong nước để xác quy trình cảnh báo nguy cơ cạn kiệt, thiếu nước phục vụ quản lý tài nguyên nước hiệu quả dựa trên giá trị kinh tế sử dụng nước [3-13] áp dụng thử nghiệm trên LVS Sê San phần thuộc Kon Tum và Gia Lai. Quy trình nghiên cứu gồm 2 bước chính: (1) Xác định giá trị kinh tế sử dụng nước (dựa trên các phương pháp và số liệu thực tế phù hợp); (2) Xác định nguy cơ thiệt hại, rủi ro GTKTSDN các ngành.

\subsubsection{Xác định GTKTSDN}

Dựa trên cơ sở lý thuyết nghiên cứu về giá trị kinh tế nước, các nhà kinh tế đã phát triển các phương pháp thực nghiệm để xác định giá trị kinh tế tài nguyên nước. Về cơ bản có 3 cách phân loại các phương pháp xác định GTKTSDN [20]:

Bảng 1. Nhóm phương pháp xác định GTKTSDN.

\begin{tabular}{ccccc}
\hline \multirow{2}{*}{ Young (2014) [5] } & $\begin{array}{c}\text { Birol et al. (2006) } \\
{[21]}\end{array}$ & \multicolumn{2}{c}{ Dixon et al. (2013) [22], Knowler et al. (1997) [23] } \\
\cline { 3 - 5 } & Gián tiếp & $\begin{array}{c}\text { MP, RCM, ACM, AEM, } \\
\text { PFA, COI, NFI }\end{array}$ & Thị truờng giả định & Thị trường thay thế \\
\hline Quy nạp & Trực tiếp & & CVM,CEM, CM, & RPM \\
Suy luận (phân tích) & & & RIM & \\
\hline
\end{tabular}


Đối với LVS Sê San, việc xác định GTKTSDN cần có phương pháp xác định với các ràng buộc về số liệu thu thập (chi phí nhân công, chi phí vật chất), đối tượng sử dụng nước (nông nghiệp, công nghiệp, chăn nuôi, thủy điện, thủy sản) còn hạn chế nên trong nghiên cứu dựa trên các ưu nhược điểm của các phương pháp ở nghiên cứu [20] lựa chọn phương pháp (Residual Imputation Method-RIM) với đặc điểm sau:

Trong phương pháp số dư RIM), xác định mức đóng góp vào số sản phẩm gia tăng của mỗi nhân tố đầu vào trong quá trình sản xuất. Thông qua sức mạnh thị trường, nếu giá được ấn định hợp lý cho tất cả các đầu vào, trừ đầu vào không bao gồm nước thì phần giá trị dư lại trong tổng giá trị sản phẩm chính là giá trị của nước. Việc tìm ra giá trị của phần dư đòi hỏi hai tiên đề cơ bản: (1) Cân bằng cạnh tranh yêu cầu giá của tất cả tài nguyên phải bằng với thu nhập tại biên. Nhà sản xuất tối đa hóa thu nhập bằng cách tăng các yếu tố sản xuất cho đến khi giá trị sản phẩm biên bằng với chi phí cơ hội của các đầu vào; (2) Tổng giá trị sản phẩm có thể được chia thành nhiều phần, để mỗi tài nguyên được trả theo năng suất biên của nó và qua đó giá trị của các yếu tố đầu vào coi như chia sẻ toàn bộ tổng giá trị sản phẩm. Thuyết Euler cho biết rằng tổng giá trị sản phẩm sẽ được phân chia chính xác bởi các phần phân phối chỉ khi nào hàm tổng giá trị là tuyến tính thuần nhất [20].

Khi một quá trình sản xuất được xem xét trong đó có bốn yếu tố sản xuất cụ thể là vốn $(\mathrm{K})$, lao động $(\mathrm{L})$, tài nguyên thiên nhiên khác $(\mathrm{R})$ và nước $(\mathrm{W})$ được sử dụng để sản xuất một đầu ra duy nhất $\mathrm{Y}$, thì hàm sản xuất có thể viết như sau:

$\mathrm{TVP} \gamma=(\mathrm{VMPK} * \mathrm{QK})+(\mathrm{VMPL} * \mathrm{QL})+(\mathrm{VMPR} * \mathrm{QR})+(\mathrm{VMPW} * \mathrm{QW})$

Trong đó $\mathrm{TVP} \gamma$ là tổng giá trị của sản phẩm $\gamma$; VMP là giá trị sản phẩm biên của yếu tố sản xuất; $Q$ là số lượng của yếu tố sản xuất.

Giá trị kinh tế sử dụng nước tính bằng giá trị biên:

$$
\mathrm{PW}=\mathrm{TVP} \gamma-[(\mathrm{PK} * \mathrm{QK})+(\mathrm{PL} * \mathrm{QL})+(\mathrm{PR} * \mathrm{QR})] \mathrm{QW}
$$

Trong đó $\mathrm{TVP}_{\gamma}$ là giá trị của sản phẩm; $(\mathrm{PK} * \mathrm{QK})+(\mathrm{PL} * \mathrm{QL})+(\mathrm{PR} * \mathrm{QR})$ là tổng chi phí sản xuất nông nghiệp; $\mathrm{PK}, \mathrm{QK}$ là các giá trị vốn và số lượng ban đầu tham gia vào quá trình sản xuất ra 1 sản phẩm; PL, QL là chi phí nhân công lao động và số nhân công lạo động tham gia vào quá trình sản xuất ra 1 sản phẩm; $P R, Q R$ là chi phí tài nguyên và số lượng tài nguyên tham gia vào quá trình sản xuất ra 1 sản phẩm; $Q W$ là lượng nước dùng tham gia vào quá trình sản xuất ra 1 sản phẩm.

Giá trị kinh tế sử dụng nước tính bằng giá trị trung bình (trường hợp chưa xác định được chi phí nhân công và vật chất):

$$
\mathrm{Pw}_{\mathrm{w}}=\frac{\mathrm{TVP} \gamma}{\mathrm{Q}_{\mathrm{w}}}
$$

Trong đó $\mathrm{Pw}$ là giá trị kinh tế sử dụng nước $\left(\mathrm{d} / \mathrm{m}^{3}\right) ; \mathrm{TVP} \gamma$ là giá trị của sản phẩm; $\mathrm{Q}_{\mathrm{w}}$ là lượng nước dùng tham gia vào quá trình sản xuất ra 1 sản phẩm.

\subsubsection{Xác định nguy cơ thiệt hại, rủi ro GTKTSDN các ngành}

Dựa trên kết quả của bước 1 là xác định kết quả tính toán giá trị kinh tế sử dụng nước và kết quả xác định nguy cơ hạn hán, thiếu nước các ngành dựa trên kết quả tính toán tổng lượng tài nguyên nước, kết quả tính toán cân bằng nước phần 2 tỉnh thuộc lưu vực là Kon Tum và Gia Lai [24-25] sẽ xác định tổng thiệt giá trị kinh tế sử dụng nước các ngành tương ứng các kịch bản được xây dựng được xác định như sau:

$$
\mathrm{LPw}_{\mathrm{Pw}}=\mathrm{LPw}^{*} \mathrm{Lt}
$$

Trong đó $\mathrm{LPw}$ là thiệt hại GTKTSDN (đồng); $\mathrm{Pw}$ là giá trị kinh tế sử dụng nước $\left(\mathrm{d} / \mathrm{m}^{3}\right)$; Lt là lượng nước thiếu $\left(\mathrm{m}^{3}\right)$.

\subsection{Số liệu thu thập}

- Định hướng phát triển KTXH đến 2030 các tỉnh nằm trong lưu vực; 
- Nhu cầu sử dụng nước trong các giai đoạn tính toán 2017, 2030 trên lưu vực;

- Tiêu chuẩn quốc gia TCVN 8641:2011 về Công trình thủy lợi-Kỹ thuật tưới tiêu nước cho cây lương thực và cây thực phẩm;

- Tiêu chuẩn quốc gia TCVN 4454:2012 về Quy hoạch xây dựng nông thôn-Tiêu chuẩn thiết kế;

- Giá chi phí sản xuất và thành phẩm trên thị trường của các đối tượng sử dụng nước lưu vực Sê San: (1) Trồng trọt; (2) Chăn nuôi; (3) Thủy sản; (4) Công nghiệp;

- Niên giám thống kê Kontum, Gia Lai 2017, 2018,2019;

- Báo cáo thuyết minh quy hoạch tài nguyên nước lưu vực sông Sê San-Srê Pốk, Dự án Quản lý tổng hợp Tài nguyên nước Mê Công, 2020.

\section{Kết quả và thảo luận}

\subsection{Kết quả tính toán giá trị kinh tế sủ dụng nước}

Việc xác định giá trị kinh tế sử dụng nước dựa trên phương pháp RIM với 2 nhóm tiếp cận: (1) Giá trị biên và (2) Giá trị trung bình như đã đề cập ở mục Phương pháp nghiên cứu. Đối với nghiên cứu này, nhóm tác giả dựa trên tình hình số liệu xác định GTKTSDN đối với các nhóm đối tượng chính bao gồm: (1) Nhóm trồng trọt gồm lúa và ngô; (2) Nhóm chăn nuôi gồm bò và lợn; (3) Nhóm thủy sản; (4) Nhóm công nghiệp.

Phương pháp được sử dụng là cách tiếp cận giá trị trung bình (do điều kiện về số liệu hạn chế của 2 tỉnh) đối với toàn bộ các đối tượng sử dụng nước để từ đó đưa ra mẫu chung về giá trị kinh tế sử dụng nước, công bằng trong việc xác định các ngành mang lại giá trị sản xuất trong trong đó có sử dụng nước hiệu quả.

Bảng 2. Kết quả GTKTSDN của các đối tượng dùng nước trên lưu vực sông Sê San (Đơn vị: đồng/m³).

\begin{tabular}{lcccccc}
\hline GTKTSDN & Lúa & Thủy sản & Ngô & Lọn & Bò & Công nghiệp \\
\hline Kontum & $1.339,22$ & $18.495,30$ & $8.336,10$ & $191.780,82$ & $753.424,66$ & $245.300,06$ \\
Gia Lai & $1.728,62$ & $5.765,77$ & $10.400,00$ & $191.780,82$ & $753.424,66$ & $534.234,76$ \\
LV Sê San & $1.533,92$ & $12.130,53$ & $9.368,05$ & $191.780,82$ & $753.424,66$ & $389.767,41$ \\
\hline
\end{tabular}

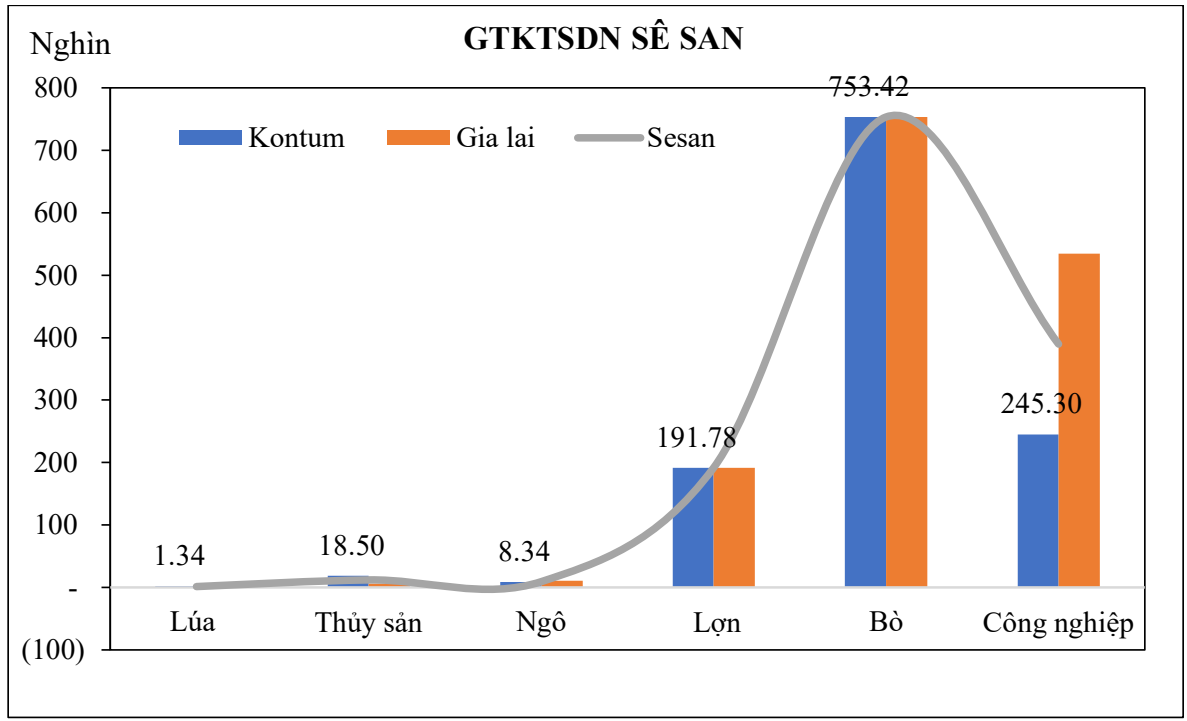

Hình 2. GTKTSDN các đối tượng dùng nước trên LVS Sê San.

Giá trị kinh tế đối với nông nghiệp và chăn nuôi được xác định tương ứng giá trung bình của 2 đối tượng bên trong như sau: 
Bảng 3. Kết quả GTKTSDN đại diện các ngành trên lưu vực sông Sê San (Đơn vị: đồng/m³).

\begin{tabular}{ccccc}
\hline GTKTSDN & Nông nghiệp & Chăn nuôi & Thủy sản & Công nghiệp \\
\hline LVS Sê San & $5.450,98$ & $472.602,74$ & $12.130,53$ & $389.767,41$ \\
\hline
\end{tabular}

Có thể nhận thấy xu hướng ở thời điểm gần đây đối với lưu vực sông Sê San là phát triển công nghiệp và chăn nuôi dựa trên nhu cầu sử dụng nước các ngành làm căn cứ. nông nghiệp với GTKTSDN chăn nuôi đạt 472.602,74 đ/ $/ \mathrm{m}^{3}$, sau đó là công nghiệp với $389.767,41 \mathrm{~d} / \mathrm{m}^{3}$.

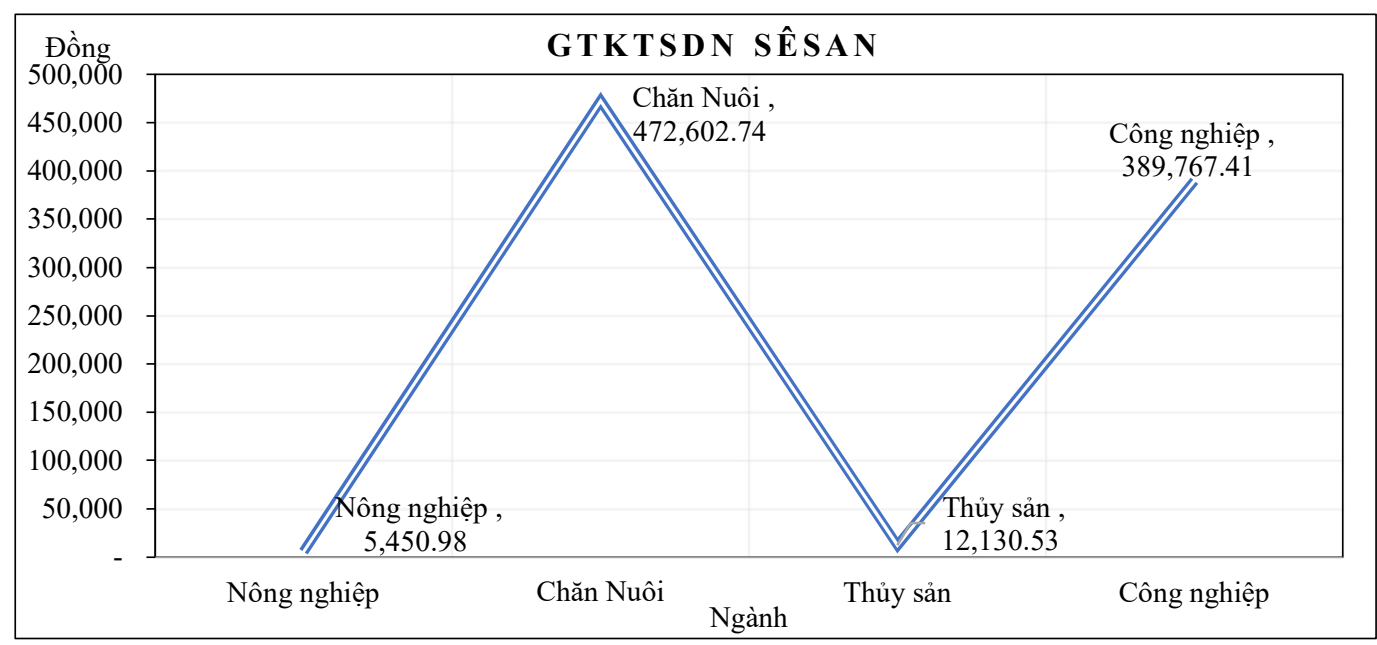

Hình 3. GTKTSDN đại diện các ngành trên LVS Sê San.

Bảng 4. Các thành phần xác định giá trị kinh tế sử dụng nước lưu vực sông Sê San tham chiếu [25-27].

\begin{tabular}{|c|c|c|c|c|c|}
\hline \multicolumn{6}{|c|}{ Lúa } \\
\hline $\begin{array}{c}\text { Địa } \\
\text { phương }\end{array}$ & $\begin{array}{c}\text { Sản lượng } \\
\text { (tấn) }\end{array}$ & $\begin{array}{c}\text { Giá } \\
\text { (triệu/tấn) }\end{array}$ & $\begin{array}{l}\text { Diện tích } \\
\text { (ha) }\end{array}$ & $\begin{array}{c}\text { Giá trị sản xuất } \\
\text { (triệu đồng) }\end{array}$ & Tổng lượng nước $\left(\mathbf{m}^{3}\right)$ \\
\hline Kontum & $91.010,00$ & 6,00 & $23.985,00$ & $546.060,00$ & $407.745 .000,00$ \\
\hline Gia lai & $354.583,00$ & 6,00 & $72.397,00$ & $2.127 .498,00$ & $1.230 .749 .000,00$ \\
\hline \multicolumn{6}{|c|}{ Thủy sản } \\
\hline $\begin{array}{c}\text { Địa } \\
\text { phương }\end{array}$ & $\begin{array}{c}\text { Sản lượng } \\
\text { (tấn) }\end{array}$ & $\begin{array}{c}\text { Giá } \\
\text { (triệu/tấn) }\end{array}$ & $\begin{array}{c}\text { Diện tích } \\
\text { (ha) }\end{array}$ & $\begin{array}{c}\text { Giá trị sản xuất (triệu } \\
\text { đồng) }\end{array}$ & $\begin{array}{c}\text { Tổng lượng nước } \\
\left(\mathbf{m}^{3}\right)\end{array}$ \\
\hline Kontum & $4.425,00$ & 40,00 & 638,00 & $177.000,00$ & $9.570 .000,00$ \\
\hline Gia lai & $2.400,00$ & 40,00 & $1.110,00$ & $96.000,00$ & $16.650 .000,00$ \\
\hline \multicolumn{6}{|c|}{ Ngô } \\
\hline Địa phương & $\begin{array}{c}\text { Sản lượng } \\
\text { (tấn) }\end{array}$ & $\begin{array}{c}\text { Giá } \\
\text { (triệu/tấn) }\end{array}$ & $\begin{array}{l}\text { Diện tích } \\
\text { (ha) }\end{array}$ & $\begin{array}{c}\text { Giá trị sản xuất } \\
\text { (triệu đồng) }\end{array}$ & $\begin{array}{c}\text { Tổng lượng nước } \\
\left(\mathbf{m}^{3}\right)\end{array}$ \\
\hline Kontum & $24.856,00$ & 5,20 & $6.202,00$ & $129.251,20$ & $15.505 .000,00$ \\
\hline Gia lai & $15.630,00$ & 5,20 & $3.126,00$ & $81.276,00$ & $7.815 .000,00$ \\
\hline \multicolumn{6}{|c|}{ Lọn } \\
\hline Địa phương & $\begin{array}{r}\text { Sản lu } \\
\text { (tấl }\end{array}$ & $\begin{array}{r}\text { C } \\
\text { (triệ }\end{array}$ & $\begin{array}{l}\text { Yiá } \\
\text { u/tấn) }\end{array}$ & $\begin{array}{c}\text { iá trị sản xuất (triệu } \\
\text { đồng) }\end{array}$ & Tổng lượng nước $\left(\mathrm{m}^{3}\right)$ \\
\hline Kontum & 132.88 & 0,00 & 88,00 & 35,00 & $465.080,00$ \\
\hline Gia lai & 85.00 & 8.5 & 0,00 & 35,00 & $297.500,00$ \\
\hline & & & Bò & & \\
\hline Địa phương & $\begin{array}{c}\text { Sản lượng } \\
\text { (tấn) }\end{array}$ & $\begin{array}{r}\mathrm{C} \\
\text { (triệ }\end{array}$ & iá & $\begin{array}{c}\text { Giá trị sản xuất } \\
\text { (triệu đồng) }\end{array}$ & Tổng lượng nước $\left(\mathrm{m}^{3}\right)$ \\
\hline Kontum & $395.000,00$ & 98.7 & 50,00 & 110,00 & $10.862 .500,00$ \\
\hline Gia lai & $77.880,00$ & 19.4 & 70,00 & 110,00 & $2.141 .700,00$ \\
\hline
\end{tabular}


Công nghiệp

\begin{tabular}{cccc}
\hline Địa phương & Giá trị sản xuất (tỉ đồng) & Diện tích (ha) & Tổng lượng nước $\left.\mathbf{( m}^{\mathbf{3}}\right)$ \\
\hline Kontum & $4.524,43$ & 631,66 & $18.444 .472,00$ \\
Gia lai & $18.080,00$ & 1159 & $33.842 .800,00$ \\
\hline
\end{tabular}

\subsection{Kết quả tính toán nguy co thiệt hại, rủi ro GTKTSDN các ngành}

Kết quả tính toán xác định thiệt hại về GTKTSDN giai đoạn nền 2017 và kịch bản 2030 trong tương lai trong điều kiện thiếu nước được thể hiện chi tiết trong bảng 5 . Dựa trên kết quả cân bằng nước xác định lượng nước thiếu và giá trị kinh tế sử dụng nước các nghành đã được tính toán trong đó. Trong điều kiện nguồn nước đáp ứng đủ cho các nhu cầu các ngành được cấp đủ $100 \%$, tuy nhiên, trong điều kiện thiếu nước thì vấn đề sử dụng nước phải được xem xét và quyết định bởi nhà quản lý dựa trên thiệt hại về kinh tế các ngành sử dụng nước trong sinh hoạt và sản xuất.

Đối với kịch bản nền 2017 đối tượng thiệt hại về kinh tế khi thiếu nước đứng đầu là công nghiệp với 588,55 tỉ đồng, tiếp sau là chăn nuôii, nông nghiệp và thủy sản tương ứng là 458,42; 69,88; 21,59 tỉ đồng, Kết quả cho thấy kịch bản nền tập trung cấp nước cho khu công nghiệp và chăn nuôi. Đối với kịch bản định hướng 2030 đối tượng thiệt hại về kinh tế khi thiếu nước đứng đầu là chăn nuôi với hơn $2.585,14$ tỉ đồng, tiếp sau là công nghiệp, thủy sản và nông nghiệp tương ứng là $1.691,59 ; 99,96$ và 98,44 tỉ đồng. Kết quả cho thấy định hướng phát triển chăn nuôi và công nghiệp là lớn, sự phụ thuộc vào nguồn nước và lượng nước cấp cho thấy giá trị khi hạn hán, thiếu nước xảy ra.

Bảng 5. Kết quả thiệt hại, rủi ro về GTKTSDN các ngành theo các kịch bản.

\begin{tabular}{|c|c|c|c|c|c|c|c|}
\hline TT & $\begin{array}{l}\text { Ngành sử } \\
\text { dụng }\end{array}$ & $\begin{array}{c}\text { Nhu cầu } \\
\text { nước } 2017 \\
(\text { triệu m³ }\end{array}$ & $\begin{array}{c}\text { Lưọng thiếu } \\
\text { hụt kịch } \\
\text { bản } 2017 \\
(\text { triệu m³ }\end{array}$ & $\begin{array}{c}\text { Thiệt hại } \\
\text { kinh tế } \\
2017 \\
\text { (tỉ đồng) }\end{array}$ & $\begin{array}{c}\text { Nhu cầu } \\
\text { nước } \\
2030 \\
(\text { triệu m m) }\end{array}$ & $\begin{array}{c}\text { Lượng thiếu } \\
\text { hụt kịch } \\
\text { bản } 2030 \\
\text { (triệu m³ }\end{array}$ & $\begin{array}{c}\text { Thiệt hại } \\
\text { kinh tế } 2030 \\
\text { (tỉ đồng) }\end{array}$ \\
\hline 1 & Nông nghiệp & 503,87 & 12,82 & 69,88 & 673,56 & 18,06 & 98,44 \\
\hline 2 & Thuỷ sản & 12,01 & 1,78 & 21,59 & 44,60 & 8,24 & 99,96 \\
\hline 3 & Chăn nuôi & 7,64 & 0,97 & 458,42 & 65,73 & 5,47 & $2.585,14$ \\
\hline 4 & Công nghiệp & 82,57 & 1,51 & 588,55 & 198,99 & 4,34 & $1.691,59$ \\
\hline
\end{tabular}

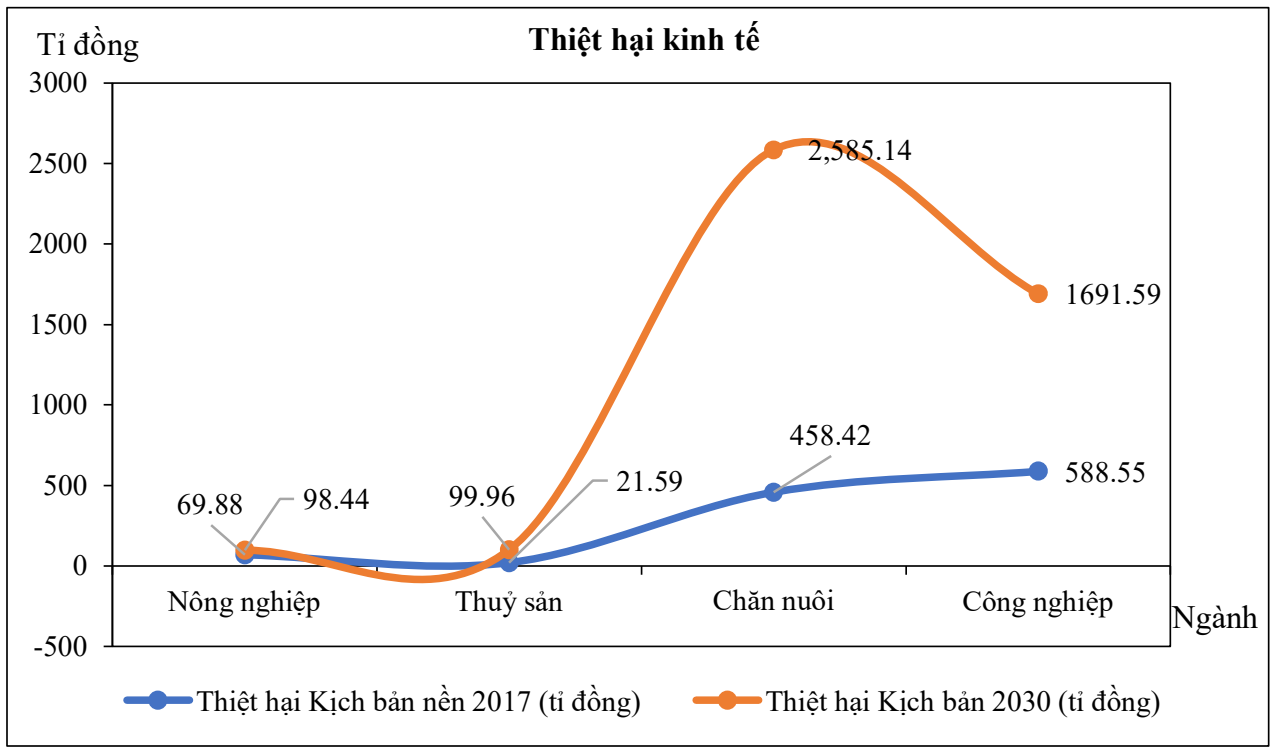

Hình 4. Thiệt hại kinh tế các ngành do hạn hán, thiếu nước gây ra. 


\section{Kết luận}

Nghiên cứu đã tiến hành nghiên cứu theo dạng bước thực hiện cho thấy quy trình cảnh báo nguy cơ cạn kiệt, thiếu nước phục vụ quản lý tài nguyên nước dựa trên phương pháp RIM tính toán giá trị kinh tế sử dụng nước các ngành, xác định nguy cơ thiệt hại về kinh tế và đưa ra vai trò của cảnh báo hạn hán, thiếu nước.

Nghiên cứu đã xác định trị kinh tế sử dụng nước của các đối tượng sử dụng nước chính để xác định nguy cơ thiệt hại kinh tế khi hạn hán, thiếu nước trên lưu lực với 5 đối tượng chính: (1) Nông nghiệp ( Lúa + Ngô); (2) Chăn nuôi (Bò + Lợn); (3) Thủy sản; (4) Công nghiệp với kết quả GTKTSDN cho chăn nuôi là cao nhất tương ứng $472.602,74$ đồng $/ \mathrm{m}^{3}$ với đặc thù sử dụng nước hiệu quả và giá thành thịt hơi cao, tiếp sau đó là công nghiệp với $389.767,41$ đồng $/ \mathrm{m}^{3}$ với đặc thù sử dụng nước khá hiệu quả với giá trị sản xuất cao, Thủy sản thứ 3 với 12.130,53 đồng $/ \mathrm{m}^{3}$ với diện tích đang nuôi không lớn, sau cùng với đặc thù giá thành bán không cao và lượng nước sử dụng lớn với GTKTSDN hơn $5.450,98$ đồng $/ \mathrm{m}^{3}$ của nông nghiệp.

Trên cơ sở giá trị kinh tế sử dụng nước và lượng nước thiếu dựa trên 2 kịch bản cân bằng nước tính toán thiệt hại, rủi ro giá trị kinh tế nước xác định đối với : (1) Kịch bản nền 2017 đứng đầu là công nghiệp với 588,55 tỉ đồng, tiếp sau là chăn nuôi, nông nghiệp và thủy sản tương ứng là 458,42; 69,88; 21,59 tỉ đồng; (2) Kịch bản định hướng 2030 đối tượng thiệt hại về kinh tế khi thiếu nước đứng đầu là chăn nuôi với hơn 2585,14 tỉ đồng, tiếp sau là công nghiệp, thủy sản và nông nghiệp tương ứng là 1691,59;99,96; 98,44 tỉ đồng.

Kết quả nghiên cứu đề xuất quy định kỹ thuật cảnh báo nguy cơ cạn kiệt, thiếu nước mặt phục vụ quản lý tài nguyên nước hiệu quả dựa trên giá trị kinh tế sử dụng nước các đối tượng chính sau đó áp dụng thử nghiệm lưu vực sông Sê San đã cho thấy được vai trò của cảnh báo hạn hán, thiếu nước sẽ là vấn đề cần tập trung ngay tại hiện tại và về sau đối với các ngành dùng nước dựa trên GTKTSDN cần mở rộng các đội tượng để có bức tranh tổng quan và chi tiết về giá trị của nước đối với toàn bộ các ngành: thủy điện, môi trường, nước thải,... Do vậy, cần có những nghiên cứu mới xác định các yếu tố liên hệ giữa nước và các đối tượng sử dụng nước nhằm mở ra những kết quả mới về phát triển nước bền vững như Chính phủ đã đề ra.

Đóng góp của tác giả: Xây dựng ý tưởng nghiên cứu: L.T.M.V., N.H.A.; Lựa chọn phương pháp nghiên cứu: L.V.M.V., N.H.A., B.T.B.N., T.V.H.; Thu thập, phân tích, tính toán xử lý số liệu: N.H.A., T.V.H.; Viết bản thảo bài báo: N.H.A., B.T.B.N., L.T.M.V., D.Q.T.; Chỉnh sửa bài báo: N.H.A., B.T. B.N., L.T.M.V., D.Q.T.

Lời cảm ơn: Bài báo được hoàn thành dựa trên kết quả nghiên cứu đề tài cấp bộ "Nghiên cứu cơ sở khoa học và thực tiễn nhằm đề xuất bổ sung, hoàn thiện quy định về cảnh báo, dự báo TNN", mã số TNMT.2018.02.06.

Lời cam đoan: Tập thể tác giả cam đoan bài báo này là công trình nghiên cứu của tập thể tác giả, chưa được công bố ở đâu, không được sao chép từ những nghiên cứu trước đây; không có sự tranh chấp lợi ích trong nhóm tác giả.

\section{Tài liệu tham khảo}

1. Vân, L.T.M. Nghiên cứu cơ sở khoa học và thực tiễn nhằm đề xuất bổ sung, hoàn thiện quy định về dự báo, cảnh báo tài nguyên nước. Đề tài cấp bộ Mã số: TNMT.2018.02.06

2. Cục Thông tin khoa học và công nghệ quốc gia. Quản lý tài nguyên nước tổng hợp Tình hình quản lý tài nguyên nước tại Việt Nam, 2015. 
3. Kasbohm, J.; Grothe, S.; Steingrube, W.; Lài, L.T.; Ngân, L.Đ.; Hồng, N.T.; Oanh, L.T.K.; Hương, N.Q. Integrated water resources management (iwrm) - an introduction. J. Geol. B 2009, 33, 3-14.

4. Ward, F.A.; Michelsen, A. The economic value of water in agriculture: concepts and policy applications. Water Policy 2002, 4(5), 423-446.

5. Young, R.A. (Eds.). Determining the Economic Value of Water Concepts and Methods. Tayor \& Francis, New York, 2014, 358. https://doi.org/10.4324/9780203784112.

6. Dar, A.A.; Shah, H.A. Economic value of water resources of South Kashmir, India. Int. Res. J. Social Sci. 2021, 10(2), 27-29.

7. Ma, M.; Gao, S.; Lu, Y.; Yao, Y. Economic value of agricultural water use for $\begin{array}{llllll}\text { Arizona. Int. } \quad J . & \text { Electr. } & \text { Eng. }\end{array}$ https://doi.org/10.1177/0020720920984685.

8. Park, S.Y.; Yoo, S.H. Economic Value of Water in the Korean Manufacturing Industry. Water Resour. Manage. 2012, 58(1), 403-407.

9. Lowe, B.; Oglethorpe, D.; Choudhary, S. Dataset on the in-stream and off-stream economic value of water. Data Brief 2020, 30, 105434.

10. Aubuchon, C.P.; Morley, K.M. The Economic Value of Water: Providing Confidence and Context to FEMA's Methodology. J. Homeland Secur. Emergency Manage. 2013, 10(1), 2194.

11. Schnegg, M.; Kiaka, R. The economic value of water: The contradictions and consequences of a prominent development model in Namibia. Econ. Anthropol. 2019, 6(2), 264-276.

12. Adelsman, H.R.; Bloomgren, P.A. The economic value of water. Prepared for the Legislative Commission on Minnesota Resources. Minnesota Department of Natural Resources, Division of Waters, 1987, pp, 22.

13. Kulshreshtha, S.N.; Brown, W.J. The economic value of water for irrigation: a historical perspective. Can. Water Resour. J. 1990, 15(3), 201-215.

14. Hội đồng Quốc gia về tài nguyên nước. Tổng quan ngành nước Việt Nam, 2008.

15. Viện Quy hoạch Thủy lợi miền Nam. Nghiên cứu ứng dụng mô hình phân tích kinh tế GAMS trong đánh giá tài nguyên nước, thử nghiệm cho lưu vực sông Lá Buông, 2009.

16. Cục Quản lý tài nguyên nước. Nghiên cứu cơ sở khoa học và thực tiễn định giá trị tài nguyên nước cho ngành nông nghiệp, sinh hoạt, thủy điện và một số ngành công nghiệp chính trên lưu vực sông Hương, 2010.

17. Khiêm, Đ.V. và cs. Tính toán cầu và giá trị kinh tế của nước tưới. Trường Đại học Thủy Lợi, 2012.

18. VNMC. Giới thiệu về lưu vực sông Sê San-Srê Pốk. https://vnmc.gov.vn/luu-vucsong-se-san-Srê Pốk/.

19. Báo cáo thuyết minh quy hoạch tài nguyên nước lưu vực sông Sê San - Srê Pốk. Dự án Quản lý tổng hợp Tài nguyên nước Mê Công, 2020.

20. Hà, N.N. Nghiên cứu phương pháp ước tính giá trị kinh tế sử dụng nước trong quy hoạch tài nguyên nước, áp dụng thử nghiệm cho lưu vực sông Vệ. Đề tài cấp bộ Mã số: TNMT.2016.02.49, 2016.

21. Birol, E.; Karousakis, K.; Koundouri, P. Eonomic valuation techniques to inform water resourcesmanagement: A survey and critical appraisal of available techniques and an application. 2006. 
22. Dixon, J.A.; Carpenter, R.A.; Fallon, L.A.; Sherman, P.B.; Manipomoke, S. (Eds.). Economic Analysis of the Environmental Impacts of Development Projects. Routledge, London, UK, 2013, pp. 148. https://doi.org/10.4324/9781315066240.

23. Knowler, D.; Strand, I.; Barbier, E.B. An Economic Analysis of Black Sea Fisheries and Environmental Management. Final Report, The Black Sea Environment Programme, The World Bank/UNEP Global Enviromental Facility, Istanbul, Rome. 1997.

24. Báo cáo thuyết minh quy hoạch tài nguyên nước lưu vực sông Sê San-Srê Pốk. Dự án Quản lý tổng hợp Tài nguyên nước Mê Công. 2020.

25. Haskoning DHV Vietnam. Mô hình mô phỏng lưu vực 2S-Mike Hydro Basin (Dự án Quản lý Tổng hợp Tài nguyên nước sông Mê Công), 2019.

26. Kontum. Niên giám thống kê năm 2017, 2018, 2019.

27. Gia Lai. Niên giám thống kê 2017, 2018, 2019.

\title{
Research and propose a process to warn of the risk of water depletion and shortage for effective water resource management based on the economic value of water use
}

\author{
Le Thi Mai Van ${ }^{*}$, Nguyen Hung Anh ${ }^{1}$, Doan Quang Tri², Bui Thi Bich Ngoc ${ }^{1}$, Truong \\ Van Hung ${ }^{1}$ \\ ${ }^{1}$ National Center for Water Resources Planning and Investigation; \\ lethimaivantnn@gmail.com; hunganhtnn@gmail.com; bichngoc209hunre@gmail.com; \\ truongvanhung888@gmail.com \\ ${ }^{2}$ Vietnam Journal of Hydrometeorology, Viet Nam Meteorological and Hydrological \\ Administration; doanquangtrikttv@gmail.com
}

\begin{abstract}
The risk of water depletion and lack of water is a hot issue in every country in the world and in Vietnam. The warning, forecasting and management of water resources are the basis for identifying risks and providing solutions in managing and using water effectively. The study is based on the RIM method and identifies the risk of economic damage to water-using industries in the context of drought and water shortage based on warnings about water resources in the Sesan River basin. Results of determination of economic value of water use (Economic value of water): Animal husbandry 472,602.74 $\mathrm{VND} / \mathrm{m}^{3}$; Industry $389,767.41 \mathrm{VND} / \mathrm{m}^{3}$; Seafood $12,130.53 \mathrm{VND} / \mathrm{m}^{3}$; Agriculture $5,450.98$ $\mathrm{VND} / \mathrm{m}^{3}$. Determining economic losses and risks of water use with the scenario in 2030 , livestock is the leading with more than 2,585.14 billion VND, followed by industry, fisheries and agriculture, respectively, 1,691.59; 99.96; 98.44 billion VND/year. The process of warning about the risk of water depletion and lack of water for effective management of water resources based on the economic value of water use greatly supports the effective management and planning of water resources.
\end{abstract}

Keywords: Economic value of water use; Water Resources; Warning about the risk of water shortage; Drought and lack of water. 